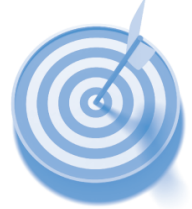

T G Harrison* and
D E Shallcross
School of Chemistry
University of Bristol
Cantock's Close
Bristol
BS8 1TS

*t.g.harrison@bris.ac.uk

W B Davey

Department of Chemistry

University of Sheffield

Sheffield,

S10 2TN

It was a long-standing desire of the Outreach team at the School of

Chemistry at Bristol to utilise the teaching laboratory space more frequently...

\section{Making better and wider use of undergraduate teaching laboratories in the support of chemistry in the UK}

\begin{abstract}
The Chemistry Departments at Bristol and Sheffield Universities have adopted two complementary approaches to maximising the use of teaching laboratory space, in the main to support secondary school level study. The two approaches involve the adaptation of a small part of a teaching laboratory or the use of the whole of the undergraduate teaching laboratories themselves. In the former case a small number of students can enjoy their use throughout the week and in the latter a large number of students can use the facilities one day per week in undergraduate term time and in the remaining 18 weeks of the year when not required for undergraduate teaching. This paper describes the development and the challenges to be overcome with both scenarios and the advantages and disadvantages of both approaches, using an example from each.
\end{abstract}

\section{Introduction}

Many UK chemistry departments admit secondary school students to their teaching laboratories on occasions throughout the year, whether it is part of a school spectroscopy visit for Post 16 students $^{1,2}$ for chemistry competitions such as the Royal Society of Chemistry's Top of the Bench and Analytical Chemistry competitions or the Salters' 'Challenge'. Some chemistry departments use their facilities as part of summer schools such as the Salters' Camps ${ }^{3}$ and for Widening Participation ${ }^{4,5}$ activities such as those run for the Sutton Trust ${ }^{6}$. These engagements are put on as a collective desire to promote chemistry, to assist local and regional chemistry teachers by providing practical opportunities that are not possible at secondary school and as part of the promotion of the advantages of Higher Education generally. Some will undoubtedly use such activities to promote their own departments ${ }^{2}$. Historically such activities would be delivered with little funding, by committed individuals, whether academics or postgraduate students, and involving small numbers of students per year.

\section{Outreach at Bristol ChemLabS}

Since the creation of Bristol ChemLabS in 2005 it sought to establish a wide-ranging programme of public engagement, in addition to providing state-of-the-art professional-standard teaching laboratories. The laboratories were equipped with research-grade instrumentation with embedding of e-learning and e-assessment alongside more conventional teaching methods to improve undergraduate student experiences $^{7,8}$. As part of this project a secondary school teacher joined the staff with the main aim of utilising the School of Chemistry's facilities for outreach regionally, nationally and internationally, as well as to provide congruence in teaching between secondary and tertiary level Chemistry ${ }^{2,9-11}$.

There are two floors of teaching laboratories at Bristol, each can accommodate 108 undergraduates doing individual practical work, with no separation between organic, inorganic or physical chemistry based experiments. It was a long-standing desire of the Outreach team at the School of Chemistry at Bristol to utilise the teaching laboratory space more frequently, when not being used in undergraduate teaching. Clearly, these facilities could be used to both promote and support the teaching of chemistry at secondary school level and to the general public and could possibly be used to generate an income to keep the laboratories up to a very high standard ${ }^{2,12}$. There are about 18 weeks per year when schools are in session and undergraduates are not using the labs either because the undergraduates are at home or in examinations. In Bristol, the labs are also not used on Wednesdays. This leaves plenty of time when school groups could use them quite apart from the times when they are used to host summer schools and day activities in some of the school holiday periods. 
The School Teacher Fellow at Bristol, working with technical staff and the Outreach Director, drew up a portfolio of practical activities that could be carried out in the labs for secondary students from all years, and resourced and trialed them early in the history of the Bristol ChemLabS project. The favoured practical activities, those that could not be done in schools (e.g. because of a lack of sufficient equipment such as fumehoods, because of a lack of experience or simply because of timetable constraints) were then up-scaled. The 'standard' practical work on offer for Post-16 students naturally involves organic chemistry as the amount of equipment in schools cannot match that available at a university. The extraction of caffeine from tea bags, which involves electric heating mantles, Buchner filtration, cooling in ice-baths, solvent extraction and rotary evaporation with infrared spectroscopic analysis is one favourite. Up to 80 students working in pairs can be accommodated. A second organic practical is a more involved synthesis of a solid anaesthetic, which also includes thin layer chromatography and melting point determination. Other practicals provided for younger students include circuses of polymer experiments, colour chemistry experiments and green chemistry. Perfume chemistry workshops for primary aged students in years 5 and 6 (10-11 year olds) are also organised as are practical sessions supporting large numbers of students for preuniversity assessed (examination) work and several teacher requested/bespoke sessions.

All outreach practicals use glassware specifically set aside for schools work so that there is less time taken up with changing over from undergraduate practicals. To engage with large numbers of students in one sitting requires the training and payment of a large number of postgraduate chemistry demonstrators. Bristol normally staffs engagement activities at a ratio of 12 students to one demonstrator and we will also have the School Teacher Fellow and technical staff on hand. If accompanying teachers wish to participate in either the experiments or in the demonstrating of the experiments this is encouraged. It is not unusual for visiting groups, sometimes from 3 or 4 schools per session, travelling up to 2.5 hours for a day visit, to make a full day of the visit by enjoying talks and a lecture demonstration in the afternoon; some of the talks being presented by postgraduates. Autumn, Spring and Summer schools see students and school groups regularly arriving from Ireland, Malta, Spain, France and Italy with schools in the Far East considering participation in coming years.

Of the $25,000-30,000$ students engaged directly by Bristol ChemLabS outreach per year, approximately 2000 per year work in the labs. The organisation of this requires considerable technical, secretarial and other support from the department as well as a large contribution of time from postgraduate volunteers. The latter are not only financially rewarded but also gain considerable soft skills much in demand by employers ${ }^{13}$. This is managed sustainably by charging for activities at full cost whether directly to the schools, through Impact requirements of research grants, specific outreach grants or donations by alumni ${ }^{12}$.

Part of the success of Bristol ChemLabS Outreach is that specific practical sessions are available from one year to another and the quality of the student experience is consistently high because of stability of lead staff and the standard of training of the postgraduates. In addition, school teachers know that the STF is a well respected teacher and that the experience will map well to not only the formal curriculum but also the wider aspirational goals of any visit. The scaffolding provided by the STF for any visit, in terms of preliminary material sent to teachers (health and safety information, practical scripts etc.) has maximised the impact of any activity ${ }^{14-16}$. Although it was not an objective of the project, undergraduate recruitment has been influenced positively by the open labs project ${ }^{17}$. The sharing of best practice with groups from other countries has been an extremely beneficial facet of this project. Having colleagues from other countries sharing their best practice with us has only enhanced the experience for Bristol Undergraduates and the schools we have engaged with.

\section{Challenges faced by Bristol ChemLabS outreach include:}

- Matching the demand for spaces during undergraduate term time.

There is of course a natural limit on the number of places available to use the laboratory during term time and this is an inevitable draw-back of the Bristol ChemLabS approach.

- Impact of the 'rarely cover' policies in schools. In order to combat this we run competitions in the evening. However, to do this on a regular basis puts too much strain on support staff that have to give up evenings.

- Convincing some funding bodies that the number of students we can work with in the promotion of chemistry is realistic and not a flight of fantasy.

This is an area that continues to frustrate.

The immediate future for Bristol ChemLabS is that the laboratories will continue to be used in this way for at least the next three years but with no end in sight. A business plan was written to cover this timescale and despite the economic downturn (which was a factored contingency) the plan is working very well. The development of the use of the laboratory space by an increasing number of residential schools both by school students and for teacher training is set to increase. At the time of writing the bookings for the laboratories are 11 months in advance.

\section{University of Sheffield Schools Laboratory}

The USSL project involved the creation of a small (up to 15 students plus teachers) high specification laboratory which opened in November 2007. Here groups of students could carry out practical work that was not normally carried out in school or college. The laboratory possesses six large, high specification fume cupboards under which is stored a comprehensive range of apparatus.

A little used laboratory in the heart of the undergraduate teaching laboratories was selected for conversion into the dedicated facility. This central position was chosen as it would allow visiting students to gain a sense of what undergraduate students experience during the practical aspects of their course. The large sliding doors to the USSL were constructed entirely from glass designed to create a sense of being amongst the 50 , or so, undergraduate students within the larger physical chemistry laboratory. 
It was felt that school and college students would benefit from access to a dedicated university facility in which they could have the time to develop their practical skills and knowledge beyond what was normally possible in school. The constraints upon practical work range from the prohibitive cost of chemicals or the perceived risk of carrying out certain reactions through to the simple fact that students rarely have the chance to have several hours in a lab in any single session. Furthermore, the experience of being in a university department, alongside undergraduates and postgraduates, was expected to have a motivational effect in terms of their consideration of university education and, more specifically, on their choosing chemistry.

To achieve our objective, funding was provided by NESTA and by the Royal Society of Chemistry through the Chemistry for our Future (CFOF) program ${ }^{18}$ (Strand 4, Widening Schools' Access to University Laboratories.). This funding allowed the University of Sheffield to create the 'nuts and bolts' of the University of Sheffield Schools Laboratory (USSL). The majority of staffing costs during the first year of the USSL were initially borne by the RSC, again through the CFOF program (Strand 2; School

Teacher Fellowship). Will Davey, one of the RSC School Teacher

Fellows (2007/2008) was

appointed to the Department of Chemistry. One of his objectives was to use his expertise as an experienced chemistry teacher at a local Sheffield secondary school (King Edward VII School) to develop and deliver relevant practical work to students from KS2-5. Initially this involved him equipping the laboratory with the necessary apparatus and appropriate chemicals. A number of companies and organisations were keen to help support the creation of the USSL. For example, Sigma-Aldrich Chemicals have provided chemicals, free of charge, and have pledged to continue this arrangement. Naturally, this has made the success of the USSL more secure. Their UK website has a link to the USSL.

Currently, the day to day running of the laboratory is carried out by a Schools Liaison Coordinator, employed on a fixed term contract by the Department of Chemistry and by the department's School Teacher Fellow (1 day per week). A small amount of technical support is provided by a chemistry technician from the undergraduate teaching labs.

Administrative and secretarial duties are carried out by the School Liaison Coordinator.

A range of activities are available in the USSL but the most regularly requested and popular activity has been the synthesis of paracetamol. The two stage synthesis has fitted perfectly into a day in the USSL. The students' samples of paracetamol have then been analysed by ${ }^{1} \mathrm{H}$ NMR 'while they wait'. This 'hands on' approach, using machines that students will not see in school has been an extremely popular end to the session. Schools can book longer 'Spectroscopy Afternoons' where they get to analyse unknown compounds by mass spectrometry, IR spectroscopy and ${ }^{1} \mathrm{H}$ NMR spectroscopy. These sessions, additional to the USSL sessions, are offered on Wednesday afternoons and become fully booked for most of the year.

No charges are made for use of the USSL or the Spectroscopy courses, although this policy is one that is under continued review. Nor are charges made for our outreach activities such as visits to primary schools. In the past twelve months, the Department of Chemistry has engaged with almost 1000 Y5 and Y6 students in their schools.

To date, around 3000 school and college students have used the USSL. The age range has been Y5 through to Y13 although the vast majority of these have been KS5 students. The schools have attended from as far afield as Manchester to Grimsby and Huddersfield to north Birmingham.

Unsolicited verbal and written comments from students and staff that have used the lab have been universally positive. There have been several examples of the students' experiences having had a decisive effect on their choosing chemistry at undergraduate level. The impact on the university has been positive for several reasons. Most directly, the university has benefitted from students choosing to study at the University of Sheffield. Less quantifiable is the effect that the work has had on the way in which the community views the university. It has been the intention that the local community views the university as a partner that can augment the experiences of school and college students.

The positive impact on chemistry teachers visiting the USSL should also be considered. Many teachers have commented upon their enjoyment of the visit and how a day in the university has refired their own love of chemistry.

\section{Other Schools' Laboratories}

Other schools chemistry laboratories up and running in British universities include those at Liverpool and Newcastle. One lab is thought to be in the planning stage at Imperial College London.

At Newcastle a $£ 250,000$ refurbishment converted a derelict undergraduate chemistry laboratory into a new outreach laboratory equipped to university standard. An adjacent room offers ICT facilities. The costs were met as a result of a major fund-raising campaign in 2010. Newcastle has its own School Teacher Fellow in charge of the facilities as an 'outreach officer' ${ }^{19}$.

At Liverpool 'The SchoolsLab', opened during Science Week 2007 and can host groups of 15 visiting students. As with Sheffield and Newcastle the accommodation is an existing small laboratory. There is a requirement for a 'modest contribution' towards running costs for most events and sessions, intended for use by students from 10 to 18 years of 
age, run throughout the academic year. This lab, along with the others highlighted here is also used in teacher training. The SchoolsLab is sponsored by the Ogden Trust and the Engineering and Physical Sciences Research Council (EPSRC). For information on Liverpool's programmes please see <www.liv.ac.uk/chemistry/SchoolsLab/index.html>.

\section{What is the impact of using such facilities?}

The Royal Society of Chemistry (RSC) also commissioned 2 reports $^{20-22}$ as part of the evaluation of the Chemistry For Our Future (CFOF) on the use of the two laboratories at Bristol and Sheffield as 'Strand 4: Better Use of Laboratories' Bristol has also had the use of its facilities in delivering outreach activities the subject of research projects by two Masters level students $^{14,15,23}$

The RSC used short pro forma to gather feedback from young people and teachers attending three student-focused careers events in early 2009. The information gathered was analysed by the National Foundation for Educational Research (NFER) as part of the RSC's evaluation of the CFOF extension phase ${ }^{21}$. The analysis showed that visits to university laboratories their contact with staff, undergraduate and postgraduate students:

- raised student's aspirations about going to university;

- improved student's attitudes towards and images of chemistry;

- improved student's perceptions of chemistry and view it as 'practical, fun, interesting and exciting;

- students gained practical skills and opportunities to develop more detailed and complex experiments at the university sessions thus enhancing their chemistry knowledge and skills and

- improved chemistry uptake and achievement at GCSE (at 16 years of age) and in pre-university chemistry courses.

The authors are not aware of any intended follow-up study to monitor long term impact of this cohort.

The longer-term and wider impacts for pupils include impressions and perceptions of chemistry and Higher Education (HE) with their use of university lab facilities having an impact positively on the general uptake of $\mathrm{HE}$, recruitment to the host university and university chemistry ${ }^{17}$. The latter is important because young people engaged are able to make more informed choices about chemistry degrees having visited a chemistry department. This fact has been shown by the work of Shaw et $a \beta^{\beta}$, where the impact on choice of degree was significant following attendance at a series of summer schools.
More specific research into outreach impact was carried out by researchers at Bristol. Tuah ${ }^{15}$ questioned 49 students from 3 schools of 14-16 year old students about their various attitudes towards science after their involvement with the lecture demonstration on 'A Pollutant's Tale' and a polymer science workshop held in the undergraduate teaching laboratories ${ }^{3}$. Overall, Shaw ${ }^{23}$ found that the Bristol ChemLabS project was having a lasting impact because of the congruence between what was being provided for the students and what they already knew. The language, scientific terminology and scientific levels were all well matched to the incoming school students, an important result of the impact of using a School Teacher Fellow.

Significantly, a Percentage Positive Response (PPR) of more than $90 \%$ indicates students' positive views that a job related to science or career of or related to science would be interesting. About four-fifths of the students felt that the work of scientist is good for them, whereas about three quarters of the students thought that it would be interesting to earn a

living in a scientific community. Four-fifths of the students also thought that they would enjoy being scientists, but only about three-fifths of the respondents thought that they would like to work as scientists ${ }^{23}$.

Overall, a PPR of $82.6 \%$ indicates the students' positive views about a career in science whereas only $15 \%$ were non-committal and $2.4 \%$ disagreed with the idea that a career in science would be interesting. In the same study the majority of the teachers attending responded that the outreach activity was a very good way of promoting the learning of the science concepts among their students. The practical workshop was highly valued by the majority of the teachers, stating that their students were given the opportunities to perform experiments that are inaccessible in school.

Shaw $^{23}$ measured the impacts of several outreach activities over time. A few of her results are reported here.

(a) Data was obtained on applicants to Bristol's School of Chemistry since $2005 / 2006$. This was combined with information on schools engaged with Bristol ChemLabS outreach, to identify applicants that came from engaged schools ${ }^{17}$.

- Analysis at school level showed that in the period 2006-2008, engaged schools had a significantly higher average number of applicants than non-engaged schools.

- Students from engaged schools were significantly less likely to decline a place if offered one. 
(b) Identical questionnaires were given to attendees of the Chemistry Experience Camp in 2008 and 2009, and responses were compared over time. This short residential course was open to students considering applying for chemistry at any university in the UK. All students in 2008 and almost all in 2009 planned to apply for a chemistry related degree (there were some students considering medicine), and around two thirds in both years said they planned to apply to Bristol.

(c) Secondary aged children attending a chemistry day for University of Bristol employee's children were given a short questionnaire on their enjoyment of the day after attendance ${ }^{5}$. Parents were then sent a follow up questionnaire a number of months after the event, to assess their perception of potential effects of the experience on their offspring.

- Parents' reasons for volunteering their children to attend tended to relate to helping them with their current studies, because the child was interested in chemistry or because they wanted to encourage some interest in chemistry, and to give them experience of university and science in a university.

- Parents' observations of the immediate benefits of the day to their children tended to be related to the following factors: enjoyment of the day, enthusiasm and interest in chemistry, insight into the subject and university, and increased learning of skills and knowledge.

- Parents' observations of the long term benefits of the day to their children tended to be related to the following factors: increased interest in chemistry/studying chemistry helped or will help with decisions about future study, increased confidence/ attitudes. Around a quarter of parents felt unsure about what long-term benefits might be, or that it was too early to tell.

\section{Summary and Conclusions}

There are clear positive impacts of both approaches and several common themes. First, both approaches used a School Teacher Fellow to run and direct the laboratory sessions and this was the single most important reason for the success of both projects. Second, both approaches worked from a logistical and administrative point of view and science departments could easily adopt whichever one was most appropriate to them. One does not need to build a dedicated school laboratory, but can use the existing one. Any fears about wear and tear and misuse just does not happen, provided that good communication is established with schools beforehand (an STF would do this as a matter of course). The disadvantage is that the times the laboratory maybe used is restricted in term time, but the rest of the year it can be utilised most effectively. If it is more appropriate to build a dedicated laboratory (with the cost implication) then there is a facility that can be used all year round and there is no fear of disruption to the undergraduate facilities. It can also be adapted more easily for use by other groups such as primary aged students or those with disabilities and this would be a distinct advantage. In terms of the range of experiments that can be covered, both approaches are equal in their scope.

Third, the impact on both sets of providers in having a regular throughput of schools is an important one, providing constant feedback and updating from secondary school teachers. For example this may provide deeper insight into examination board emphasis on particular experiments or terminology used with practical or lecture components of such visits. Whilst this is less important in the curriculum broadening visits it is very important in events designed to support the curriculum.

The issue of sustainability of the two approaches is an important one. Funding a laboratory through departmental or University funds is possible up to a point. However, it is impossible to fund the throughput at Bristol ChemLabS from departmental or university funds. Therefore, as the project grows this problem must be tackled and the only option is to charge for activities or find a sponsor or both. At the USSL a Schools Liaison Coordinator is funded for 4 days per week through money obtained from variety of events such as delivery of the RSC's Chemistry for Non-Specialists and not centrally by the department. Here also the long-term funding of this post is uncertain.

Bristol ChemLabS trains and uses postgraduate students to demonstrate and assist with lab sessions, essential for the numbers present per session whereas the USSL is run by one person, either the STF or the Schools Liaison

Coordinator. If larger numbers are accommodated per session, more staff are needed to demonstrate and the employment of postgraduates may not be possible (low numbers or unwillingness to allow them to engage in this activity). This is then an important consideration and a potential drawback to the Bristol ChemLabS approach being widely applicable.

\section{Acknowledgments}

The authors wish to thank the Higher Education Council for England (Hefce), the original funders of the Chemistry for Our Future Project. Harrison and Shallcross also wish to thank Hefce Bristol ChemLabS CETL project within which the early developmental work of the outreach programme took place. Shallcross also thanks the HEA for a National Teaching Fellowship. 


\section{References}

1. Harrison T. G., Shaw A. J., Shallcross K. L., Williams S. J. and Shallcross D. E. (2010), School-University partnerships: Lessons learned from 10 years of Spectroscopy for Teachers and Post 16 Students, New Directions, 6, 72-76.

2. Harrison T.G. and Shallcross D.E. (2010), What should be Expected of Successful Engagement between Schools, Colleges and Universities?, School Science Review, 91(35), 97-102.

3. Shaw A.J., Harrison T.G., Croker S.J., Medley M.I., Sellou L. Shallcross K.L., Williams S.J., and Shallcross D.E. (2010), University-School partnerships: On the impact on students of Summer Schools (for school students aged 17-18) run by Bristol ChemLabS, Acta Didactica Napocensia 3(4), 35-48.

4. Shaw, A.J., Harrison, T.G., Croker, S.J., Medley., M.I., Shallcross, K.L., Williams, S.J. and Shallcross, D.E. (2010), University-School partnerships: Polymer Chemistry days run at a University for 14-15 year olds and their impact on attitudes to Science, Acta Didactica Napocensia, 3 (1), 19-26.

5. Shaw, A.J., Harrison, T.G., Shallcross, D.E. and Medley, M.I. (2009), Chemistry Inreach: Engaging with University Employees' Children within a Chemistry Department, Acta Didactica Napocensia, 2 (4), 107-112.

6. <www.suttontrust.com/summer-schools/> (last accessed February 2011).

7. Harrison T.G. and Shallcross D.E. (2008), A Chemistry Dynamic Laboratory Manual for Schools, Chemistry in Action, 86, Winter, 20-22.

8. <www.chemlabs.bris.ac.uk/overview.htm (last accessed March 2011).

9. Harrison T.G., Shallcross D.E., Heslop W.J., Eastman J.R. and Baldwin A. (2009), Transferring best practice from undergraduate practical teaching to secondary schools: The Dynamic Laboratory Manual, Acta Didactica Napocensia, 2 (1), 1-8.

10. Chemistry Education Research and Practice 8, 101-104.

11. Harrison, T. G., Berry B. and Shallcross, D. E. (2010), A Festival of Contemporary Science, Education in Science, 239, 11-120.

12. Harrison, T. G. and Shallcross, D. E. (2010), Towards sustainable public engagement (Outreach), New Directions, 6, 41-46.

13. Steve Hanson and Tina Overton (2010), 'Skills required by new chemistry graduates and their development in degree programmes, Higher Education Academy UK Physical Sciences Centre.

14. Tuah J., Harrison T.G. and Shallcross D.E. (2009), The advantages perceived by schoolteachers in engaging their students in university-based chemistry outreach activities, Acta Didactica Napocensia, 2 (3), 31-44.

15. Tuah J., Harrison T.G. and Shallcross D.E. (2010), A Review of the Use of Demonstration Lectures in the Promotion of Positive Attitudes towards, and the Learning of Science with reference to a 'A Pollutant's Tale', a demonstration lecture on air quality and climate change, The Romanian Journal of Education 1(3-4), 93-102.

16. Shaw A. J., Harrison T.G. and Shallcross D.E. (2010), What Value has Chemistry Outreach by a University department to secondary schools? Teacher Perceptions of Bristol ChemLabS Outreach Events, Acta Didactica Napocensia 3(3), 15-23.
17. Shaw, A.J., Harrison, T.G., Shallcross, K.L., Williams, S.J. and Shallcross, D.E. (2011), On the impact of the Bristol ChemLabS' Outreach program on admissions to the School of Chemistry, in press New Directions (2011).

18. Tunney, J. (2009), A legacy for chemistry education, New Directions, 5, 7-11.

19. Hager Y. (2010), 'The insider: Chemical outreach' Chemistry World, Royal Society of Chemistry Publishing, $7,(8)$.

20. 20. Lord P., Straw S., Springate I., Harland J. and Hart R. (2008), 'Evaluation of Chemistry for Our Future Report on the first year of the evaluation (2007 - 2008)' National Foundation for Educational Research.

21. Lord P., Straw S., Hart R., Springate I. and Harland J. (2009), 'Evaluation of Chemistry for our Future Extension Phase Report', National Foundation for Educational Research.

22. Lord P., Straw S., Hart R., Springate I. and Harland J. (2009), 'Evaluation of Chemistry for our Future Extension Phase Appendices', National Foundation for Educational Research.

23. Shaw A.J. (2009), 'Evaluation of Bristol ChemLabS Outreach' An MSc Thesis submitted at the University of Bristol, December.

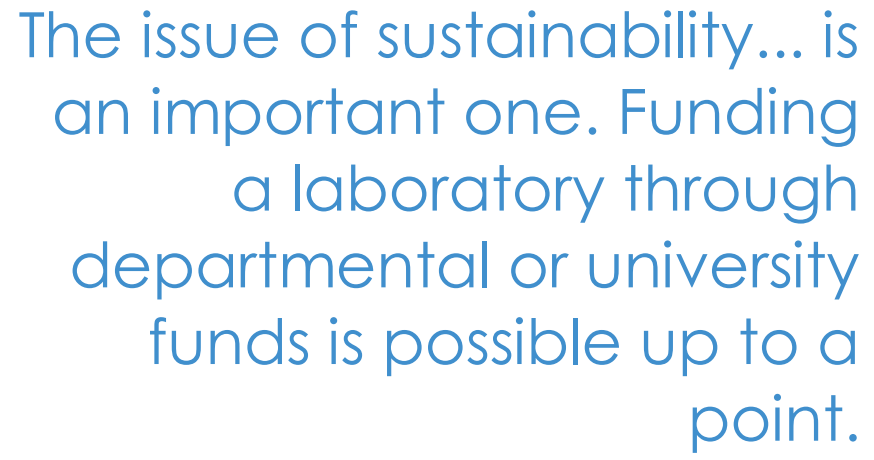

